\title{
IX foro de Rectores(as) y Orientadores(as)
}

Ángela María Hernández P. ${ }^{+++\dagger}$
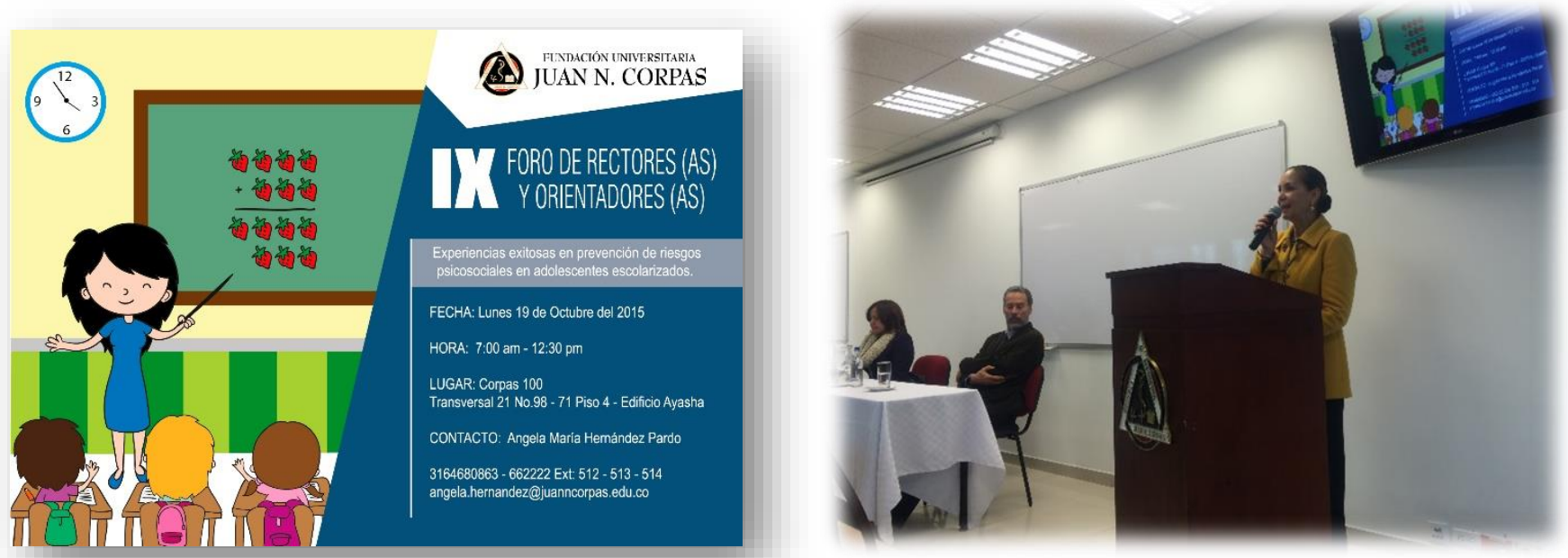

El lunes 19 de octubre de 2015 se realizó el IX foro de Rectores(as) y Orientadores(as), cuyo tema central fue "Experiencias exitosas en la prevención de riesgos psicosociales en adolescentes escolarizados". Ese día se contó con la exposición de los programas desarrollados en la Universidad Manuela Beltrán, Colegio Aníbal Fernández de Soto, Gonzalo Arango y Abraham Lincoln.

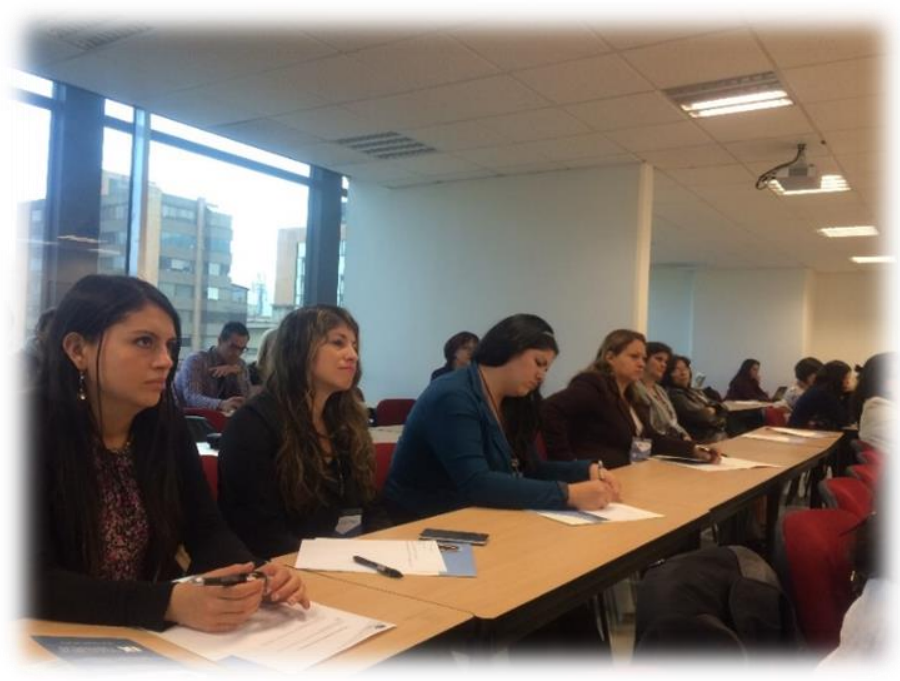

Al finalizar se realizó un conversatorio donde los diferentes participantes opinaron acerca de los programas expuestos y la necesidad de las entidades distritales para fortalecer ese tipo de iniciativas.

${ }^{+++++}$MD, Magíster Educación. Especialista en Salud Familiar. Profesor Agregado FUJNC. angela.hernandez@juanncorpas.edu.co. 


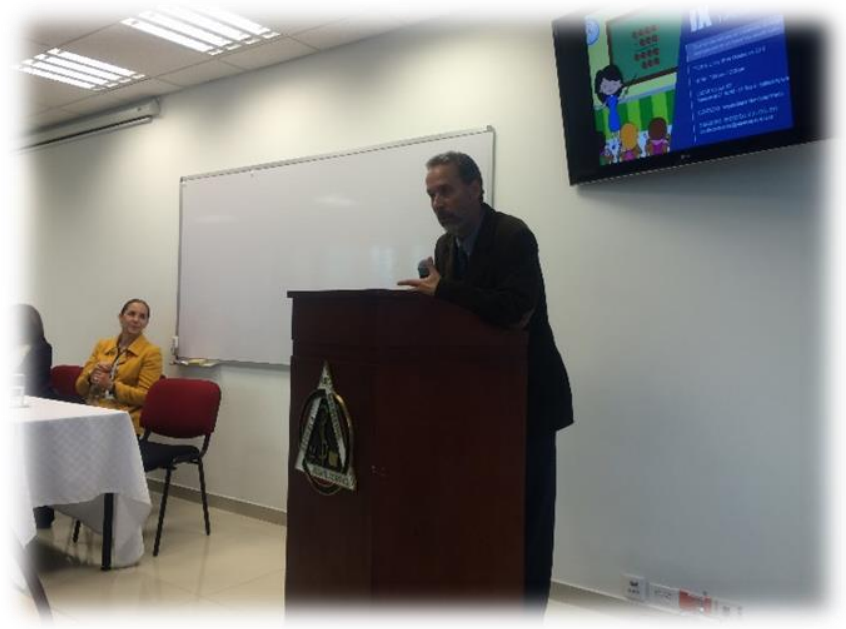

Un agradecimiento especial a la doctora Ana María Piñeros (Rectora de la FUJNC), quien con su apoyo incondicional hacia el Departamento de Medicina Comunitaria ha permitido que año tras año se desarrolle con éxito este foro.
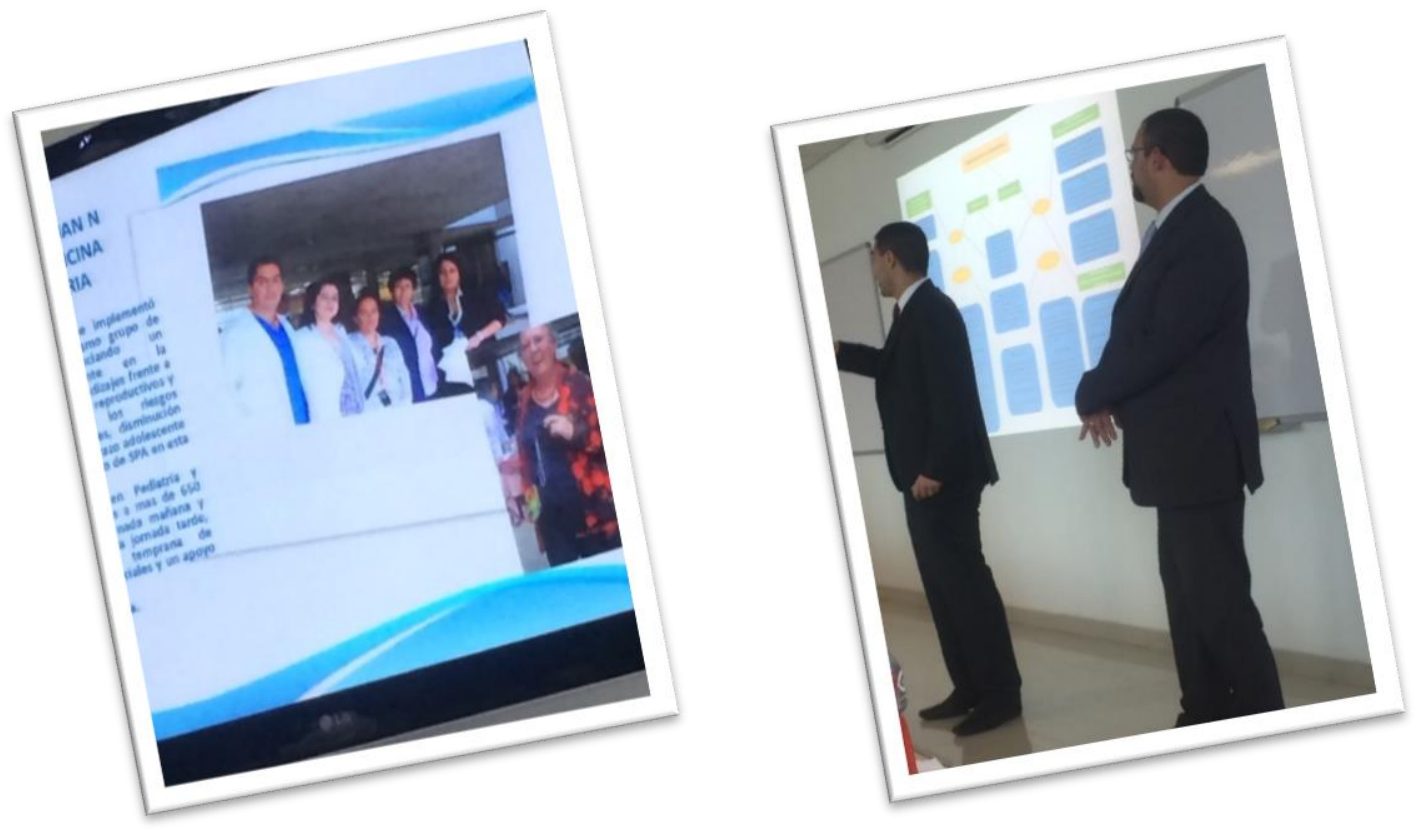

Agradecemos, de igual forma, a la Dirección Local de Educación de Suba, su directora, doctora Magnolia Agudelo, a todos los participantes, docentes del Departamento de Medicina Comunitaria, docentes de la FUJNC y en especial al Doctor Juan Carlos González, director del Departamento de Medicina Comunitaria, quien con su entusiasmo y dedicación ha permitido que encuentros como estos fortalezcan los lazos con los colegios distritales y privados de la localidad. 